\title{
The Curriculum Improvement Movement in Oklahoma
}

RAYMOND J. YOUNG

YST professionally minded persons who have worked in some phase of tions such as, "What am I actually accomplishing in the school I serve?" "How can I improve the existing educational experience for youth?" and "What elements of educational experiences are of most value or worth?" Questions such as these have plagued educators through the centuries, but inherent in the story of educational progress at all times seems to have been a conviction that something can be done by serious effort, study, and subsequent action to promote and continue the improvement of school experience.

Lessons from previous experience have indicated that an educational program which serves society and the individual effectively must continuously be in a process of re-examination and reconstruction. Great strides have been made since 1930 in studying, revising, improving, and experimenting with programs, accepting challenges, defending desirable features, and implementing changes designed to provide a more effective educational experience. These improvements have been more in harmony with the changing needs of society and youth, based upon scientific knowledge of how learning occurs, and concerned with what we know about the nature of the individual.

\section{CRITICISMS EVIDENCE CONTINUED NEED FOR IMPROVEMENT}

For a considerable time in recent year, the secondary schools of the nation have been in the spotlight of public attention. Both laymen and educators have become aware of certain weaknesses in them. Some of the most serious criticisms have come from within the ranks of the profession itself, and many of them are based on scientific studies. Laymen have voiced their criticisms through newspaper editorials, magazine articles, radio programs, and in other ways. Publications for laymen generally give prominence to topics of growing public interest. Scarcely a month elapses without one or more publications of national circulation giving attention to the schools and their strengths or deficiences in

Raymond J. Young has served as Executive Secretary of the OSSCIC since its inception and is Associate Professor of Education, University of Oklahoma. Others providing leadership to improvement activities are: F. R. Born, Treasurer, Supervisor of Secondary Education, Oklahoma City; Harry Broad, Director, Principal Daniel Webster High School, Tulsa; Roy Daniel, Chairman, Principal Norman High School, Norman; and Stan Keas, Secretary, Assistant State Superintendent of Schools in Charge of Instruction. 
serving adolescent youth. Magazines of this stature seldom allocate space to a movement unless popular demand for a subject is apparent. An examination of all periodicals published for lay consumption during the last fifteen years indicates a rapid increase in the total number of articles published about education and schools.

Educators have welcomed constructive criticisms designed to improve the schools, but they have detested irresponsible, unjust criticism made with malicious intent of destruction. A general consensus as to what the scope of reconstruction in the school program should be is seldom reached. On most issues, critics represent two extremes. Some favor discarding everything and starting anew, but others advocate a return to the status of fifty years ago. Oklahoma is no different from other states in having both types of vocal proponents. In attempting to improve the work and effectiveness of the school, it is imperative that care be exercised to prevent values secured through a long struggle from being cast lightly aside. Simultaneously, though, the requirements of society for a program to care for the additional changed educational needs must be met.

When secondary education is viewed in its true historical perspective, the evidence indicates there never has been a time when either professional educators or laymen were entirely satisfied. Throughout passing decades, some of the criticisms expressed during the establishment and development of the public secondary school have been retained and novel ones added until today, there are many. Recent increasing public interest in educational matters as reflected through the increasing magnitude of concern evidenced in literature for the layman is a healthy and wholesome sign.

Admittedly, there seems to be evidence of growing public concern that secondary schools are not sufficiently effective in terms of modern living. A reflection of this general opinion is to be found in the formation of the National Citizens Commission for the Public Schools, a legitimate worth-while organization. The increased frequency with which educators themselves are studying successful programs of curriculum improvement and planning the application of the processes to their own situations is evidence of their sensitiveness to certain deficiencies. Some of the criticisms are valid, but others are unfounded and unjust. The imperative need for improvement is further emphasized when it is realized that less than three fifths of all pupils entering high school remains to graduate, and that the average school level attained in the national population is about 8.4 grades. Only about 75 per cent of high-school-age youth enter high school.

\section{SOCIAL CHANGE NECESSITATES NEED FOR CURRICULUM STUDY}

As society changes, the needs of youth change, and thus the pattern of the school responsibility also changes. No program is useful that does not function to serve the most urgent demands thrust upon it by a dynamic civilization. Of 
all the evidence which could be marshalled to indicate the tremendous and immense gap which today exists between man's scientific advancement and his social progress, the bombs that dropped during World War II and those that have recently been exploded at Frenchman's Flat, Nevada, proving grounds are the most vivid and grim reminders. Specialized technological progress has created tensions which make social lag increasingly acute. The curriculum has been tardy in adjusting itself to the times. Inertia, insecurity, or a reluctance to part with tradition have held the school to a program long after it has ceased to be effective. Social, political, and economic changes have recently assumed such proportions that educators are today attacking curriculum improvement with renewed energy. There is need for racial experience in organized subject matter knowledge to be applied to the development of behaviors needed in successful adjustment in the world of today and for citizenship in American democracy. Many educational leaders are freeing their school programs from obsolete concepts and practices and are adopting procedures designed to meet the vital needs of all youth for life as consumers of goods and services, producers, homemakers, parents, workers, and citizens. Attempts are being made to use subject content in the classroom as a means of producing behavioral change in desired directions in the learner, and its place in the curriculum is based upon the possible contributions it can make as a tool for promoting behavior modifications rather than as an end in itself for knowledge sake. This task has presented a challenge and an opportunity to educational leaders for some time.

\section{PREVIOUS CURRICULUM IMPROVEMENT ATTEMPTS}

Attempts to improve the curriculum were first stimulated by the concerns and pressures of institutions of higher learning to assure that the product of the secondary school knew certain things believed to be necessary for successful college work. Later, additional stimulation came from demands of the business and industrial world. Improvement was strictly an individual isolated school matter of conforming to certain outside pressures. It wasn't until after the first quarter of the present century that improvement activity on an area, regional, or state basis became a concern of responsible leaders. Many earlier attempts to bring about improvement consisted in the preparation and distribution of courses of study for various grade levels and subject matter areas. This approach has generally been found to be of most value to those few persons who worked in the preparation of the guides and courses of study and of questionable value or sometimes of negative value to persons to whom they were distributed.

\section{RECENT CURRICULUM IMPROVEMENT ACTIVITIES}

During the past fifteen years, curriculum improvement efforts on an area, regional, or state basis have increased, but the nature of the approach has 
changed. Formerly, action was predicated on the assumption that a few representatives of educational interests could prepare materials offering answers and solutions to problems which they had identified and hand them down to local school systems and classrooms. More recent efforts have been designed to stimulate, promote, and sponsor activities which would cause local school faculty groups to learn the techniques and procedures of co-operative concerted group identification, study, analysis, and action in attacking local school problems. Also, certain technical and consultant type services have been made possible through widespread joint participation and effort of educators on an area, regional, or state basis.

\section{THE OKLAHOMA CURRICULUM IMPROVEMENT MOVEMENT}

Oklahoma is among those several states where curriculum improvement became such a concern of public school men that many of them banded together to motivate a curriculum improvement effort on a state-wide basis. Since the approach to this problem is different in some respects from that in other states, and since out of our experience certain things have become evident which might be of interest to others interested in such activity, the story concerning the establishment and work of the Oklahoma Secondary School Curriculum Improvement Commission, Inc., follows.

It was during the National Convention of the National Association of Secondary-School Principals in Cincinnati, Ohio, in 1952 that plans were discussed by a delegation of Oklahoma representatives to devote the spring state convention of secondary-school principals to a proposal for a curriculum improvement conference. The idea of a state-wide curriculum improvement project was discussed at considerable length by the members of a well-attended meeting. The principals enthusiastically approved the idea and authorized the executive committee of the Oklahoma Secondary-School Principals Association to activate the program and further spell out the specifics of the general accepted proposal. After considerable study and thought, a co-ordinating committee for curriculum improvement was appointed consisting of nine secondary-school principals representing each of nine Oklahoma Education Association districts, the assistant state superintendent of education in charge of instruction and director of the Division of Secondary Education; the president, treasurer, and co-ordinator of the Oklahoma Secondary-School Principals Association; two members-at-large consisting of the assistant superintendent of schools in Oklahoma City and the principal of Daniel Webster High School in Tulsa; and one consultant each from the secondary education division of Oklahoma $A \& M$ College, and the state University.

After a considerable number of meetings and careful study involving many persons during 1952 and the spring of 1953, the co-ordinating committee, after changing its name to the Oklahoma Secondary-School Curriculum Improvement 
Commission, considered and worked out definite organizational plans and became incorporated. The Oklahoma Education Association provided an equipped office space. On June 1, 1953, an executive secretary was obtained from Oklahoma A \& $\mathrm{M}$ College. He was a faculty member, released on a half-time basis upon request from the principals.

\section{BASIC WORKING ASSUMPTIONS}

Early in the planning, certain working assumptions were adopted which were to serve as a basis for later planning and action. They have also been continuously suggested for consideration of each local school faculty as being basic for effective study. They were:

Curriculum development is a continuous process.

Curriculum improvement is concerned primarily with changes in individuals.

A program of curriculum improvement in any school must start where the school is and with what it has.

Change in behavior of individuals is a slow, gradual process as a result of firsthand experience through active participation in a purposeful and meaningful endeavor.

Only local citizens, locally employed school personnel, and local pupils can effectively change the secondary-school program. Effective curriculum improvement is a grass roots $j o b$.

The school curriculum consists of all the experiences a pupil has under the guidance of the school.

Curriculum improvement is intimately related to teaching-learning situations.

Changes in relationships among staff members must precede changes in form and structure. Relationships among all participants in curriculum study must be maintained strictly along democratic lines. To approach the problem of developing a curriculum to prepare youth for living in a democracy by other than democratic methods is inconsistent. Not only must channels be provided for securing the opinions of laymen, nonteaching staff members, and pupils, but their opinions must also be utilized and respected.

Initiative in school-community curriculum study must come from the school staff under the leadership of the principal and with the active co-operation of the local board of education.

Local efforts at curriculum improvement will be more effective if they enlist the support of respected representative laymen, for there are enough competent persons in every community to effect any needed curriculum change provided they become, through participation, sufficiently aroused to the needs for change.

Basic studies such as those sponsored by the Commission should provide the facts necessary for arousing people to action.

Continuous efforts to ascertain the extent to which clearly defined objectives are being attained must be an integral part of effective curriculum development.

Creative curricular study and experimentation will not occur in an atmosphere where teachers, administrators, and supervisors do not recognize, admit, and talk about jobs they are having trouble with as well as what they do well.

The greatest single deterrent to curriculum change is a feeling of insecurity on the part of teachers and administrators who find themselves cast in an unfamiliar role. Leadership seeking to encourage experimentation must seek to shift the focus of attention from one of "teacher" and "teaching" to that of "learner" and "learning." 
The best possible curriculum provides all youth with experiences which meet the basic needs of the individual, the demands of society, and which are based upon the scientific knowledge of how learning occurs and the nature of the individual.

Although consultants may assist in helping to determine and delimit basic studies, in interpreting data and in setting up educational programs to meet needs, they cannot solve anyone's problems or propose a panacea for anyone's situation.

\section{OBJECTIVES OF THE OSSCIC}

In addition to basic working assumptions, consideration was given to the objectives which were to be sought. After a number of meetings conducted at different locations throughout the state and involving many persons, it was ultimately agreed that the Commission should work to:

1. Co-ordinate and to utilize more fully the resources of diverse lay and professional agencies and groups for improving secondary education.

2. Promote, stimulate, and conduct research studies pertinent to basic educational problems in Oklahoma on a local and state level which would lead to curriculum improvement.

3. Serve as a clearinghouse and central agency for collecting, publishing, and distributing materials and other resources for Oklahoma schools.

4. Assist in securing consultant service to participating schools.

5. Promote meetings, conferences, workshops, etc., designed to effect curricular improvement in Oklahoma secondary schools.

6. Enlist and encourage all secondary schools of the state to participate in a statewide program of curricular improvement.

7. Encourage broader participation of interested local community groups in improving the local school program.

8. Foster improvement of school-community relations.

9. Establish closer working relationships with institutions of higher learning.

10. Promote improved understanding and harmonious working relationships with each other on the part of various lay and professional groups interested in secondary education.

11. Promote a concerted and unified effort of various interested groups in sponsoring activities designed to provide for curricular improvement.

12. Encourage maximum utilization of the skill and understanding of teachers in solving local school problems.

13. Assist in interpreting to the general school public the nature of the problem confronting Oklahoma secondary schools in providing adequate education for all youth through grade twelve.

14. Keep members of participating schools informed about what is happening in curriculum study and improvement in Oklahoma and elsewhere through publications and meetings.

\section{PROCEDURES FOR INITIATING IMPROVEMENT ACTIVITIES}

After the executive secretary opened the office two years ago, a careful search was made of periodical literature published since 1940 for evidences of places where curriculum improvement projects had been initiated on an area, regional, district, or state basis. This served to provide names and places connected with recent curriculum improvement activities where information and materials could 
be obtained regarding procedures used elsewhere in initiating curriculum study with a view toward improvement. Attempts were made also to identify the elements characteristic of successful and unsuccessful attempts to provide for curriculum study and improvement on an area basis. Materials and information were subsequently requested from sources revealed by the investigation, and additional contacts were made with other states not mentioned in the literature to ascertain if additional information was available.

To obtain firsthand information relative to successful operation of a curriculum improvement program, the executive secretary visited and interviewed persons at the University of Illinois responsible for the materials, direction, and organization of the program there. Public school personnel were also interviewed in that state. Although the Commission realized that the program in Oklahoma could not be patterned after that of any other state, ideas and helpful suggestions based on others' experience were useful to the development of the local program for curriculum study and improvement. Later, on invitation from helpful interested colleagues in Illinois, several high-school principals, a member of the Oklahoma State Department of Education, and a faculty member of the University of Oklahoma attended a curriculum improvement workshop in southern Illinois where they mingled freely with school people seeking information and assistance. Incidentally, this was probably one of the most significant activities which contributed to the development of the work in this state.

Once information had been obtained regarding experiences elsewhere, an advisory committee was constituted which included representatives from each state teachers or denominational college, both white and Negro, the Oklahoma Congress of Parents and Teachers, the School Boards Association, all members of the Secondary Education Division of the State Department of Education, and most of the subject field divisions of the Oklahoma Education Association. The advisory committee has assisted in developing plans for action and in the review of study activities underway.

Conferences were conducted in various areas over the state to develop general orientation and understanding concerning the work of the Commission to that date and for the purpose of obtaining reactions from the "grass roots" concernings needs of local schools and to help in developing plans for further action. All school principals and/or superintendents in the state were invited to attend at least one of these meetings conducted by the representative from that area to the Commission with some other member of the Commission, the State Department of Education, or one of the consultants present.

Information received pointed up the need for identifying areas of common agreement concerning what might be done, ways of proceeding, and suggestions for various ways study activities might be initiated by participating schools. This co-operatively developed guide entitled, Guide for the Improvement of Curriculum in Oklaboma Secondary Schools has been printed by the State Depart- 
ment of Education and widely used in the participating schools of the state. Parts of it were designed to offer suggestions about how an interested faculty might get "off first base" in initiating a study activity.

\section{GETTING LOCAL SCHOOL ACTION STARTED}

Between certain specified times in the fall of 1953, participating school principals were asked to organize local faculties into small work groups and proceed co-operatively to identify problems and concerns related to the curriculum in their respective schools. Simultaneously, the Commission offered three suggested alternatives as courses of action that a school might wish to take in developing faculty interest, understanding, and ideas about what action might be followed in initiating a local study. They were: (1) to participate in a holding-power study, (2) to evaluate at least the program of studies and the extracurricular program of the school, or (3) to organize for co-operative identification of problems of concern to be explored within the school. This was followed by a two-day state-wide workshop for the purpose of identifying problems of common concern among the schools and to assist school faculties wishing to select one of the three alternative courses of action. College representatives met simultaneously to consider the role of the consultant and how a consultant might make the greatest contribution as a resource person. This was felt necessary because of the anticipated needs for consultant service for schools.

\section{TYPES OF ACTIVITIES PROMOTED}

Since the initial activity, two four-week curriculum improvement leadership training workshops-jointly staffed and sponsored by the Commission, the State Department of Education, the University of Oklahoma, and Oklahoma A \& M College and conducted on the campus of both major institutions-have been held. Teams of supervisory and administrative personnel were urged to attend, and approximately one hundred persons attended one or more of the workshops. Four two-week curriculum improvement workshops-each conducted by a different staff but jointly staffed by members of the local college, the State Department of Education, and, in some instances, a public school administrator-were planned for the campuses of three state teachers colleges and the university during the summer of 1955. The local Conference of Christian and Jews and the Southern Education Foundation have co-operatively participated in making workshop activities a success. The Commission has participated and co-operated with many groups in planning and conducting conference and workshop activities related to curriculum improvement.

A periodic publication of the Commission entitled, Ventures in Education, was established to disseminate ideas about study activities and promising practices in Oklahoma secondary schools. The distribution of this organ has served to stimulate ideas in schools looking for ways to begin study activities about 
what can be done and procedures used by schools in initiating study activities. Several follow-up evaluations of workshop activities and of what was being done in the participating schools have revealed that holding-power studies, community attitude studies, youth needs and problems studies, evaluation studies of the program of studies and extraclass activities, citizenship education and co-operative faculty study of the objectives of the school in terms of child growth and development have been underway. Many schools organized co-operative study of the ideas contained in the Guide as a means of learning to think and work together. A state-wide status study of the extraclass activity programs has been conducted as a basis for further development of materials which would provide local school faculties assistance in studying their own program. The Citizenship Education Program has recently been anchored with the Commission, and schools are being invited to consider this area as a fruitful one for study.

\section{PARTICIPATION REQUIREMENTS AND SERVICES PROVIDED}

Participation by schools is voluntary, and a school may participate to the extent it considers the program to be beneficial. All Oklahoma secondary schoolspublic, parochial, separate, and private-were invited and encouraged. All or some of the secondary schools within a school system may participate, but each school unit under a principal has been considered a separate unit for Commission purposes. Requirements for participation of each school unit include official approval by the superintendent and the local board of education, interest in the program evidenced on the part of faculty members, and the payment of an annual fee in the amount of five dollars minimum plus one dollar per teacher above five teachers teaching in grades 7 through 12, provided the fee for any school will not exceed fifty dollars.

Although at the beginning of the first year it was thought that, if as many as thirty or forty schools would participate a fine beginning would be made, there were 133 schools representing about eighty per cent of all Oklahoma youth participating at the close of that year. Continued interest and concern has been evidenced. This seems to be an indication that many persons are vitally concerned about improving experiences for youth of the state.

The Commission has offered both technical and consultant services to participating schools. Technical services include the development of study materials and the provision of IBM service. Consultant service has been related to methods of proceeding to initiate study activities, the proper conduct of studies, and the analysis of data.

\section{EVALUATION}

A mere, but significant beginning has been made. State convention meetings formerly devoted to hearing a speaker have been converted into group study activities and reports of curriculum improvement activities. Many organizations 
and agencies have focused their attention upon curriculum improvement. Members of the State Department of Education have organized study and leadership training activities designed to help them become more effective as consultants. Relationships among institutions of higher learning have improved as representatives work co-operatively on problems of common concern.

From our limited experience it is thought that some of the greatest weaknesses in the activities to date have been the failure to involve the advisory committee more extensively and to broaden the membership on it. Limiting the activities to only the secondary-school level has also been a limiting factor, but it has served as a starting point, and perhaps soon the elementary schools can be included in the program. The network of consultant service has not been fully developed. More small area conferences would provide for a more effective sharing of ideas and experiences. The involvement of school superintendents has been on an altogether too limited basis, for, unless they are widely involved and do participate in the activities, a very important element necessary for success has been lost. Their participation is imperative. Adequate finance has not been obtained although the State Department of Education, each major institution of higher learning, the O.E.A., and many persons have made valuable contributions of facilities and services.

It has been learned that when someone desires to initiate a project of curriculum improvement by prestige of his position, any attempt to force a program upon a local staff is quite certain to prove unsuccessful. Some of the schools have provided time on school time for important study activities, but nothing too significant happens when teachers already carrying a full teaching load originally designed to consume their energies are expected to do all the extra things on their own time which are necessary in any program of study. There is extreme danger in hastily plunging teachers into the solution of a problem before sufficient orientation, exploration, and study or in hurrying unseasoned solutions and change without being prepared to cope with the difficult blocks which inevitably develop.

\section{0th Annual Convention}

\section{OF THE}

NATIONAL ASSOCIATION OF SECONDARY-SCHOOL PRINCIPALS Saturday, February 25-Wednesday, February 29, 1956

Conrad Hilton Hotel Chicago, Illinois

Make Your Plans Now To Attend 